\title{
Purification and evaluation of glycerol teichoic acid from biofilm forming Staphylococcus epidermidis as a putative vaccine candidate
}

\author{
Mirzaei $\mathrm{B}^{1,2}$, Moosavi $\mathrm{SF}^{1,2}$, Babaei $\mathrm{R}^{2,3}$, Siadat $\mathrm{SD}^{2,3^{*}}$, Farjah $\mathrm{A}^{4}$, Shahrooei $\mathrm{M}^{5}$ \\ ${ }^{1}$ Department of Microbiology, Microbial research center, Pasteur Institute of Iran, Tehran, Iran. \\ ${ }^{2}$ Microbiology Research Center (MRC) Pasteur Institute of Iran, Tehran, Iran. \\ ${ }^{3}$ Department of Mycobacteriology and pulmonary research, Pasteur Institute of Iran, Tehran, Iran. \\ ${ }^{4}$ Young Researchers and Elite Club, East Tehran Branch, Azad University, Tehran, Iran. \\ ${ }^{5}$ Laboratory of Medical Microbiology, Department of Medical Diagnostic Sciences, KU Leuven, U.Z. Gasthuisberg, \\ Herestraat 49 CDG 8th floor, B-3000 Leuven, Belgium.
}

\begin{abstract}
Introduction: Biofilm forming Staphylococcus epidermidis is a main causative agent of infections related to medical devices. Purification and evaluation of Gly-TA polysaccharide from a biofilm-forming S. epidermidis as a putative vaccine candidate were the main goals of the current study. Methods: Taking advantage of size exclusion chromatography procedure, glycerol teichoic acid (Gly-TA) was purified from the above-mentioned strain and biochemical analyses including, Fourier Transform Infrared spectroscopy (FTIR) and Proton Nuclear Magnetic Resonance spectroscopy (H1-NMR) were conducted for the recovered polysaccharide. Results: Following PCR confirmation of a S. epidermidis strain, Gly-TA was extracted and its biochemical compositions (i.e. $\mathrm{N}$-acetyl glucose amine residues) were obtained. Conclusion: It is envisaged that Gly-TA polysaccharide could be considered as a putative vaccine to inhibit formation of biofilm by S. epidermidis.
\end{abstract}

KEYWORDS: Glycerol teichoic acid (Gly-TA), Staphylococcus epidermidis, FTIR, NMR.

\section{INTRODUCTION}

The ability to form biofilms on plastic or steel devices have been considered as one of the most frequent causes of nosocomial sepsis and associated infections in hospitalized patients with a high rate of morbidity and mortality $[1,2]$. Commensal and opportunistic pathogens on the skin such as coagulase-negative Staphylococci (CONs) and especially, Staphylococcus epidermidis, have been regarded as the popular causative agents of medical device-related infections $[2,3]$. The formations of a large amount of multilayered cells of the colonized coagulase-negative staphylococci have been confirmed by scanning electron microscopy [4]. The initial attachment is accomplished by surface proteins such as staphylococcal surface proteins (Ssp-1, Ssp-2), Bap homologue protein (Bhp), autolysin E (AtlE) and teichoic acids [5- 8]. Teichoic acids are polymers of ribitol phosphate or glycerol phosphate, found in bacteria [9]. The teichoic acid from Bacillus subtilis is a polymer in which 4-O- $\beta$-D-glucosyl-Dribitol units are joined by 1,5-phosphodiester linkages between

*Corresponding Author: Seyed Davar Siadat, Department of Mycobacteriology and pulmonary research center, Pasteur Institute of Iran, Tehran, Iran.

Email: d.siadat@gmail.com

Tel/Fax: (+98) 66968853 adjacent ribitols [10]. The inhibitory effect of raised polyclonal antibodies for biofilm formation process have been determined by taking advantage of immunization of mice using some macromolecules such as $S$. epidermidis surface proteins $(\mathrm{Sec})$ and polysaccharides such as polysaccharide intracellular adhesion (PIA/PNAG) and teichoic acids [2, 11]. Evidence shows that induced antibodies have biofilm inhibitory effects when pre- and post-immune sera are compared by semi quantitative biofilm inhibition procedure [2, 11]. Spoliopolima [12] and Litran [11] have reported the induction of effector antibodies with in vitro biofilm inhibition effect and opsonic activity by PIA vaccination in mice. Lavered [13] and colleagues have reported that immunization of mice by purified TA from Gram-positive Enterococci spp., can directly enhance polyclonal antibodies. Opsonic activity of mentioned IgGs has been observed as well. In the current study, following precise identification of a strain of $S$. epidermidis by PCR method, the purified and recovered Gly-TA was confirmed using NMR and FTIR methods, consequently. The purification of the Gly-TA from biofilm forming $S$. epidermidis and the evaluation of the abovementioned polysaccharide for further studies as a possible vaccine candidate in future were the main goals of the current study. 


\section{MATERIALS and METHODS}

\section{PCR confirmation of the strain}

Following conventional microbial tests according to the scheme utilized in Clinical Laboratory Standard Institute (2010) Guidelines [14], biofilm forming S. epidermidis ATCC 14990 (also known as wild-type strain 1457) was reconfirmed using polymerase chain reaction (PCR) taking advantage of designed SE 2232 primers (sesC gene) based on NCBI NC_004461.1 complete genome accession number [15].

\section{Purification of Gly-TA}

The ability of biofilm formation for the utilized strain was tested based on the procedure described elsewhere [16]. Moreover, Gly-TA was recovered from S. epidermidis strain 1457 based on Wergeland study [17] with slight modifications. Briefly, an isolated colony was inoculated in 2 liters of tryptocase soy broth (TSB, Difco, Becton Dickinson, Franklin Lakes, NJ, USA) at $37^{\circ} \mathrm{C}$ for $24 \mathrm{~h}$ at moderate shaking (70 $\mathrm{rpm} / \mathrm{min}$ ) condition. Grown colonies were collected by centrifugation and pellets were resuspended in $20 \mathrm{ml}$ of $50 \mathrm{mM}$ sodium phosphate buffer $(\mathrm{pH} 7.5)$ and sonicated 4 times for 30 seconds on ice. Extracts were dialyzed (12 KD) overnight against the same buffer and concentrated by Centriprep 10 (Amicon, Witten, Germany). Finally, the sample was directly loaded on equilibrated 1.6- by $100-\mathrm{cm}$ Sephacryl S-200 (Pharmacia LKB GmbH, Freiburg, Germany) with $50 \mathrm{mM}$ sodium phosphate by an AKTA purifier system (GE Health care, USA). The mentioned polysaccharide was collected by Fast Protein Length Chromatography (FPLC) at $206 \mathrm{~nm}$ wavelength [4, 18]. Recovered Gly-TA fractions $(100 \mu \mathrm{l})$ of obtained peaks were analyzed biochemically for protein [19] and the nucleic acid content in 280 and $260 \mathrm{~nm}$, respectively.

\section{Confirmation representative Gly-TA by FTIR and H1NMR}

Total carbohydrate content was determined by phenolsulphuric acid [20], using a standard curve of glucose. Finally, recovered Gly-TA was analyzed by Fourier Transform Infrared spectroscopy (FTIR) [21] (TENSOR 27 Burker instrumental averaging of 256 scans on the FTIR spectrometer) and Proton Nuclear Magnetic Resonance spectroscopy (H1NMR) according to established methods [22]. The structural formula of isolated Gly-TA from lactobacillus was used as a reference for analyzing FTIR and H1NMR patterns (http://micro.digitalproteus.com/morphology3.php).

\section{RESULTS}

Biochemical and molecular methods are helpful tools for precise identification of bacteria. Based on the biochemical methods such as hemolytic pattern, Gram staining and antibiotic susceptibility test, an obtained colony was identified as S. epidermidis and its strain (i.e strain 1457) was reconfirmed by PCR. The level of crystal violet content showed that the strain was able to produce biofilm in a different culturing condition including brain heart infusion (BHI) broth supplemented with $1 \%$ glucose and $4 \%$ sodium chloride. Analyzing the crude extract by FPLC indicated that our aforementioned polysaccharide will be eluted in the far of the void volume of the Sephacryl column. The obtained chromatograms from S. epidermidis (1457) in FPLC process has been shown in Fig. 1. Recovered Gly-TA fractions from those peaks of the FPLC chromatogram were assessed by phenol-sulphuric acid colorimetric assay. Content and amount of this macromolecule along with others are detailed in Table 1.

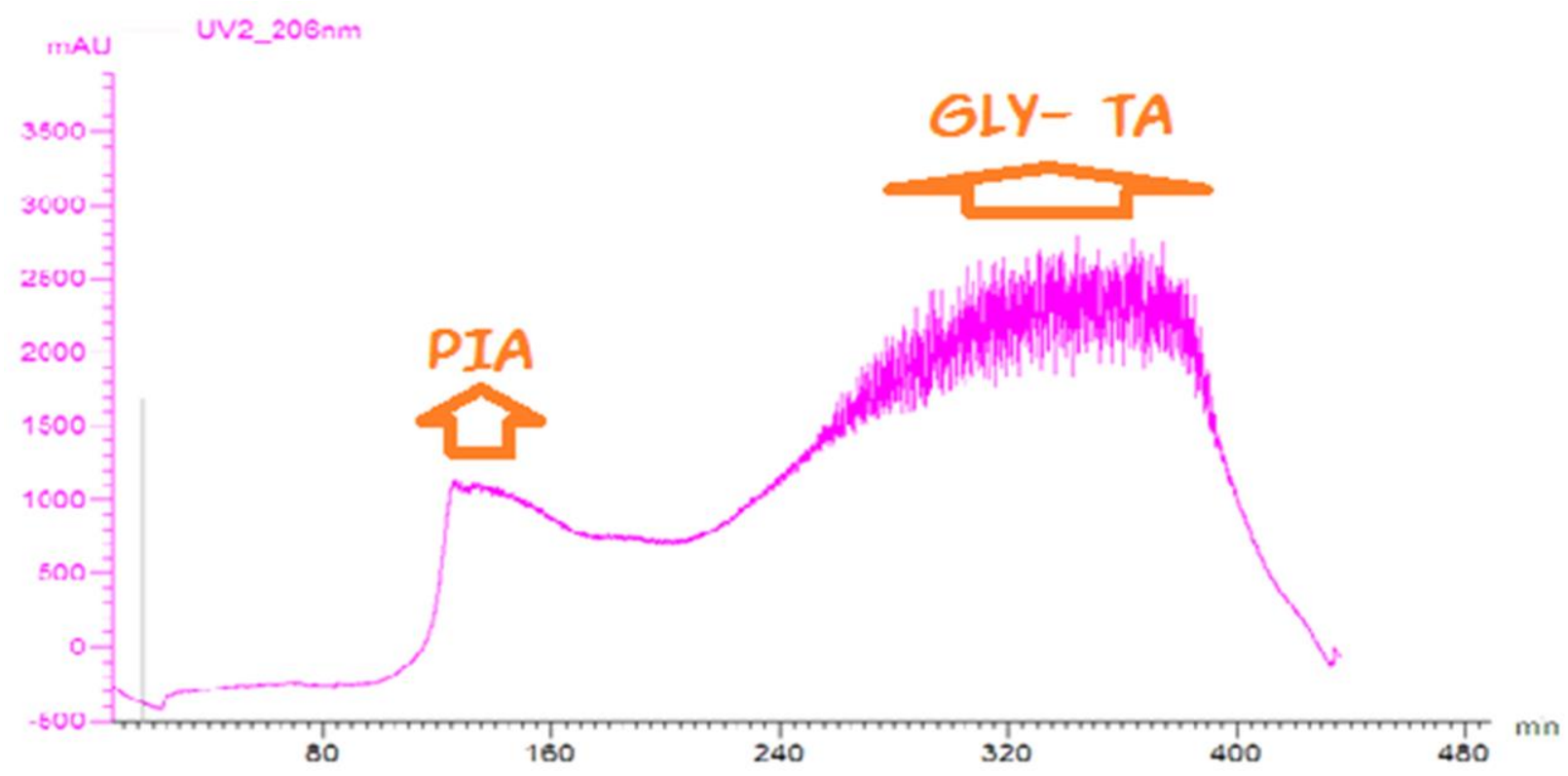

Fig. 1. FPLC graph for Gly-TA purification. Suspected Gly-TA fraction was collected and recovered Gly-TA was confirmed by phenol-sulfuric acid method. Purification was completed after equilibration of the column. The sample was eluted 105 minutes after the injection.

Gly-TA: Glycerol teichoic acid; PIA: polysaccharide intracellular adhesion. 
Table 1. Contents of carbohydrate, protein and nucleic acid in purified GlyTA, analyzed by colorimetric, Bradford and spectrophotometric assays.

\begin{tabular}{|c|c|}
\hline Content & Amount \\
\hline Carbohydrate $(\mu \mathrm{g} / \mathrm{ml})$ & 620 \\
\hline Carbohydrate $($ percentage $)$ & 62 \\
\hline Protein $(\mu \mathrm{g} / \mathrm{ml})$ & 127 \\
\hline Nucleic acid & 0 \\
\hline
\end{tabular}

Investigations concerning the adherence of S. epidermidis to biomaterials have primarily been concerned with the role of the extracellular polysaccharides or slime [3]. Gly-TA, as one of the main related factors for its inevitable role in biofilm formation process, has been considered as a suitable vaccine candidate [5]. Gel-chromatography has been described as a valid method for purification of macromolecules [23]. In this study, preparative and prepacked columns were utilized for the precise purification GLy-TA which was purified at the flow rate
$0.300 \mathrm{ml} / \mathrm{min}$ and sample of $1.5 \mathrm{ml}$ volume were collected in 5 min by a fraction collector.

FTIR has been successfully used in analyzing the composition and structure of complex chemical compounds [24]. Deconvolution method has made it possible to establish spectral characteristics of polysaccharide with Gly-TA in 4000- $400 \mathrm{~cm}$ 1 range. Spectral curves in Fig. 2 show that all the bands are observed in 3700-400 cm-1 range. Regions with stretching vibrations $v(\mathrm{CO}) \mathrm{C}-\mathrm{O}-\mathrm{C}$ Glucosylglycerol in oligosaccharides manifest its presence in the spectra of $1747-1243 \mathrm{~cm}-1$ range. The presence of the glycerol in representative Gly-TA was determined in spectra pattern 3636-2961 cм-1 as well. Our recovered polysaccharide showed similarity in structural composition with the findings mentioned in previously published studies [21] and the range was close to reports in the previous studies $[25,26]$.

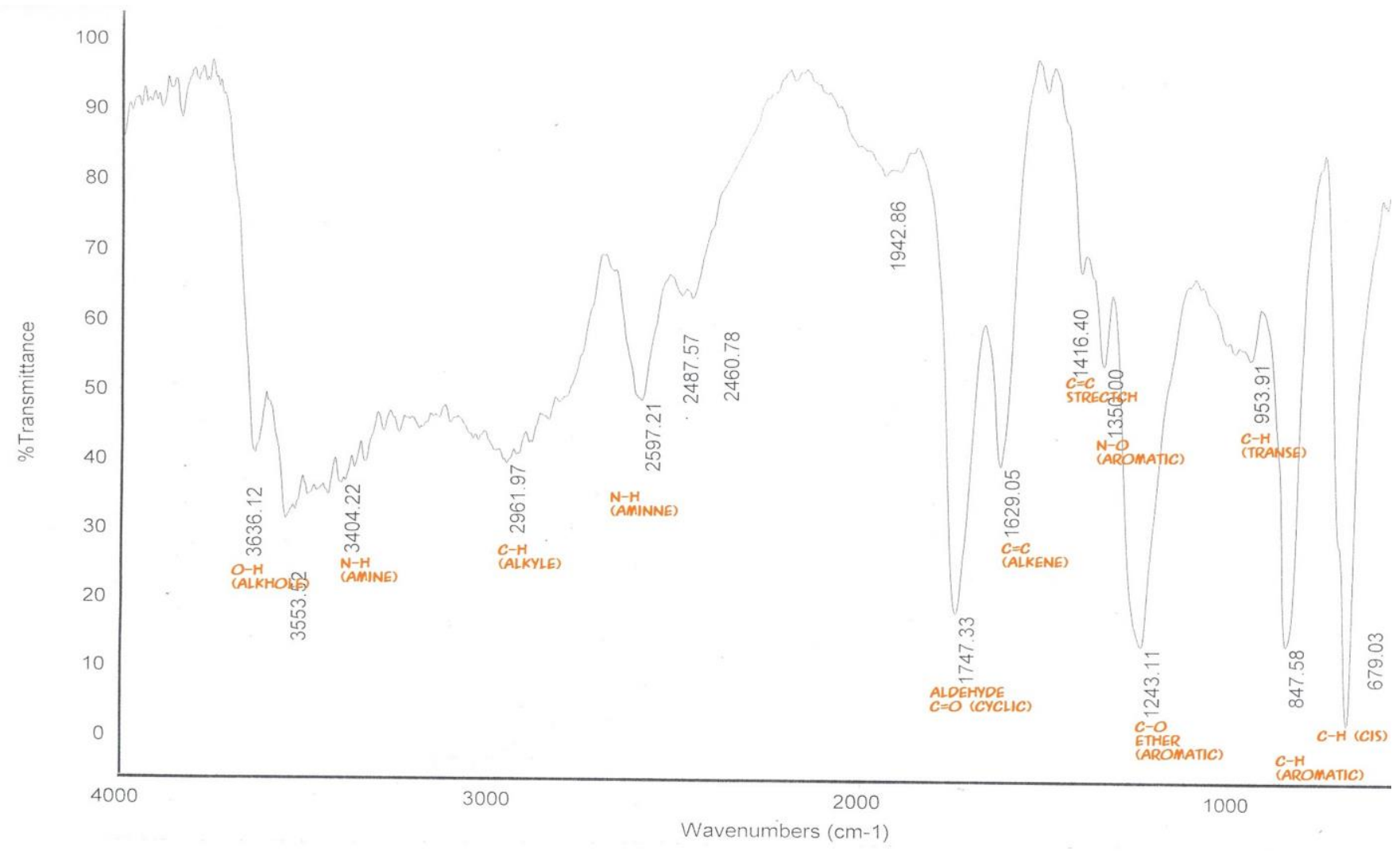

Fig. 2: FTIR pattern for recovered Gly-TA. In spectra of the 2961 and $3636 \mathrm{~cm}^{-1}$, OH and $\mathrm{CH}$ were observed as well as CO aromatic ether which was detected in $1243 \mathrm{~cm}^{-1}$. The presence of Glucosylglycerol in 1243-1747 spectra reconfirmed the purification of Gly-TA.

In the spectra of the $1747 \mathrm{~cm}-1, \mathrm{C}=\mathrm{O}$ stretch band was demonstrated. Previously, NMR spectroscopy as a precise method has been utilized for determination of extracted polysaccharide from Staphylococci [21]. In this research, onedimensional H1NMR spectra $(500 \mathrm{MHz})$ were recorded in normal acquisition mode by using 1,024 scans.

The spectra (NMR) of Gly-TA show signals attributable to (CH3)-3HPO4 residues at the $0.4 \mathrm{ppm}$. Similar data has been obtained in previous studies $[22,25]$ (Details have been shown in Fig. 3). Wicken reported that, Gly-TA has three phosphate residues structurally. In the current study using the H1NMR spectra phosphate residues were detected at the $0.1 \mathrm{ppm}$. Furthermore, correlation signal was observed for a $\mathrm{C} 2 \mathrm{H}-\mathrm{R} 3$
(H1) peak at 4- $5.1 \mathrm{ppm}[22,26]$. According to the Vinogradov and his colleague's study, a glycerol teichoic acid H1NMR spectrum has shown $\mathrm{N}$ - acetyl glucosamine residues at the 2.1$2.3 \mathrm{ppm}(\mathrm{H} 2-\mathrm{H} 6)$ as well as glycerol residues at 3.8- $4 \mathrm{ppm}$ which our data confirmed the obtained results in previous researches [26].

In conclusion, purified Gly-TA constructed by $\mathrm{N}$-acetyl glucose amine residue is a main factor for biofilm formation process. Comparison of immunogenicity and functionality raised polyclonal antibodies for SesC, Gly-TA and PIA as main related factors in biofilm forming processes are required to be investigated in the further studies. 


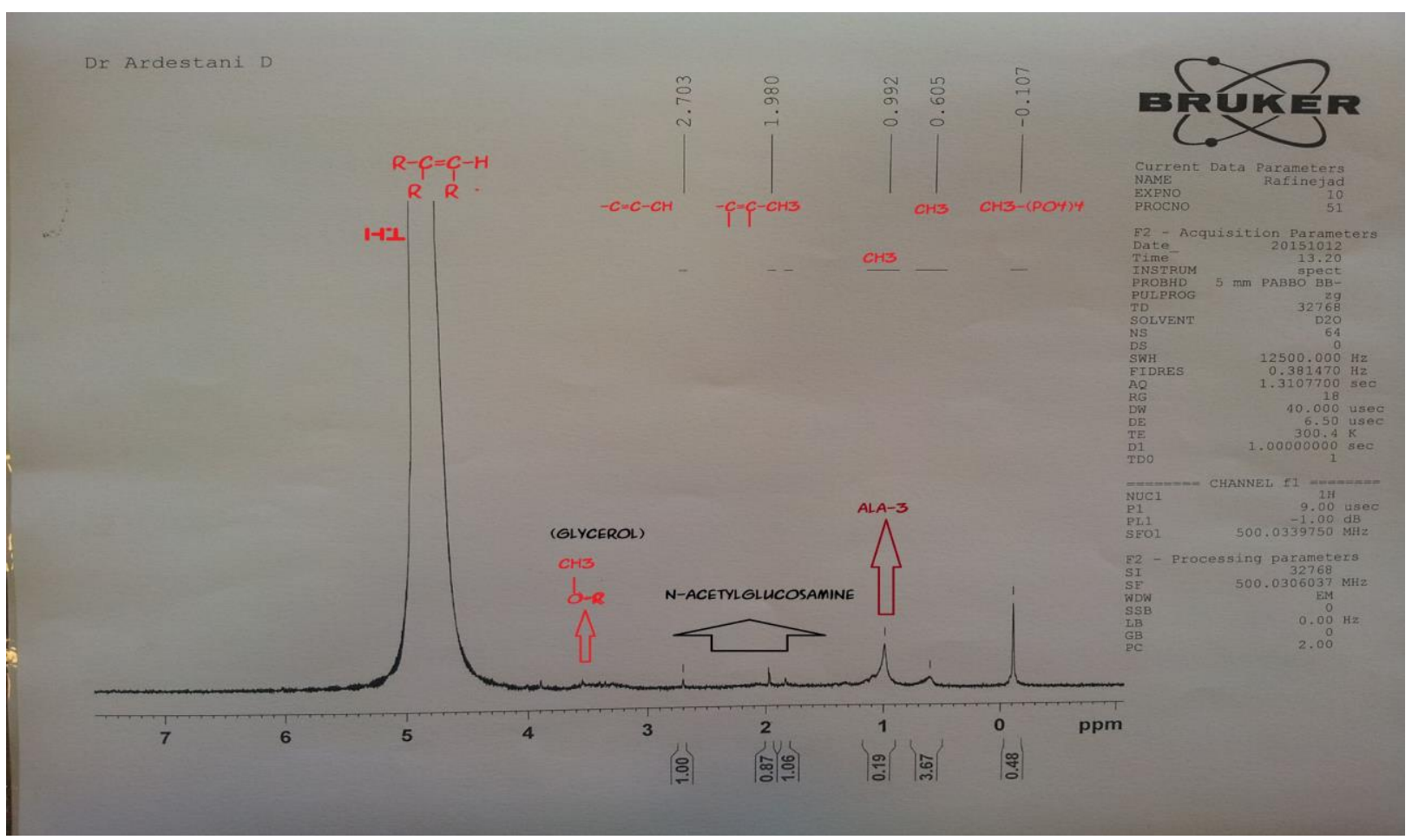

Fig. 3: $\mathrm{H}_{1}$ NMR spectrum of the cell-wall Gly-TA of S. epidermidis strain 1457. H1 and $\mathrm{H} 3$ glycerol residues indicating the presence of a [1-3] linked poly glycerol phosphate at the recovered glycerol teichoic acid $\mathrm{H}_{1} \mathrm{NMR}$ spectrum.

\section{ACKNOWLEDGEMENT}

The authors wish to acknowledge Pasteur Institute of Iran for funding as award of $\mathrm{PhD}$ scholarship under Indigenous Funding number PhD B-0098. The authors are grateful for the support of colleagues in Bacteriology and Venom Departments in Pasteur Institute of Iran.

\section{CONFLICT OF INTEREST}

The authors declare that they have no conflict of interest.

\section{REFERENCES}

1. Goldmann DA, Pier GB. Pathogenesis of infections related to intravascular catheterization. Clin Microbiol Rev. 1993;6(2):176-92.

2. Shahrooei M, Hira V, Khodaparast L, Khodaparast L, Stijlemans B, Kucharikova $\mathrm{S}$ et al. Vaccination with $\mathrm{SesC}$ decreases Staphylococcus epidermidis biofilm formation. Infect Immun. 2012;80(10):3660-8. doi:10.1128/IAI.00104-12.

3. Ziebuhr W, Krimmer V, Rachid S, Lossner I, Gotz F, Hacker J. A novel mechanism of phase variation of virulence in Staphylococcus epidermidis: evidence for control of the polysaccharide intercellular adhesin synthesis by alternating insertion and excision of the insertion sequence element IS256. Mol Microbiol. 1999;32(2):345-56.

4. Mack D, Nedelmann M, Krokotsch A, Schwarzkopf A, Heesemann J, Laufs R. Characterization of transposon mutants of biofilm-producing Staphylococcus epidermidis impaired in the accumulative phase of biofilm production: genetic identification of a hexosamine-containing polysaccharide intercellular adhesin. Infect Immun. 1994;62(8):3244-53.

5. Gross M, Cramton SE, Gotz F, Peschel A. Key role of teichoic acid net charge in Staphylococcus aureus colonization of artificial surfaces. Infect Immun. 2001;69(5):3423-6. doi:10.1128/IAI.69.5.3423-3426.2001.

6. Heilmann C, Gerke C, Perdreau-Remington F, Gotz F. Characterization of Tn917 insertion mutants of Staphylococcus epidermidis affected in biofilm formation. Infect Immun. 1996;64(1):277-82.

7. Tormo MA, Knecht E, Gotz F, Lasa I, Penades JR. Bap-dependent biofilm formation by pathogenic species of Staphylococcus: evidence of horizontal gene transfer? Microbiology. 2005;151(Pt 7):2465-75. doi:10.1099/mic. $0.27865-0$.

8. Veenstra GJ, Cremers FF, van Dijk H, Fleer A. Ultrastructural organization and regulation of a biomaterial adhesin of Staphylococcus epidermidis. J Bacteriol. 1996;178(2):537-41.

9. Salton M, Marshall B. The composition of the spore wall and the wall of vegetative cells of Bacillus subtilis. Microbiology. 1959;21(2):415-20.

10. Armstrong JJ, Baddiley J, Buchanan JG. Structure of the ribitol teichoic acid from the walls of Bacillus subtilis. Biochem J. 1960;76:610-21.

11. Maira-Litran T, Kropec A, Abeygunawardana C, Joyce J, Mark G, 3rd, Goldmann DA et al. Immunochemical properties of the staphylococcal poly-N-acetylglucosamine surface polysaccharide. Infect Immun. 2002;70(8):4433-40.

12. Spiliopoulou AI, Krevvata MI, Kolonitsiou F, Harris LG, Wilkinson TS, Davies AP et al. An extracellular Staphylococcus epidermidis polysaccharide: relation to Polysaccharide Intercellular Adhesin and its implication in phagocytosis. BMC Microbiol. 2012;12:76. doi:10.1186/1471-2180-12-76.

13. Laverde D, Wobser D, Romero-Saavedra F, Hogendorf W, van der Marel G, Berthold $M$ et al. Synthetic teichoic acid conjugate vaccine against nosocomial Gram-positive bacteria. PLoS One. 2014;9(10):e110953. doi:10.1371/journal.pone.0110953.

14. Wayne P. Methods for antimicrobial dilution and disk susceptibility testing of infrequently isolated or fastidious bacteria; approved guidelineDocument M45-A2; 2010.

15. Shahrooei M, Hira V, Stijlemans B, Merckx R, Hermans PW, Van Eldere J. Inhibition of Staphylococcus epidermidis biofilm formation by rabbit polyclonal antibodies against the $\mathrm{SesC}$ protein. Infect Immun. 2009;77(9):3670-8. doi:10.1128/IAI.01464-08.

16. Chusri S, Sompetch K, Mukdee S, Jansrisewangwong S, Srichai T, Maneenoon $\mathrm{K}$ et al. Inhibition of Staphylococcus epidermidis Biofilm Formation by Traditional Thai Herbal Recipes Used for Wound Treatment. Evid Based Complement Alternat Med. 2012;2012:159797. doi:10.1155/2012/159797.

17. Wergeland HI, Haaheim LR, Natas OB, Wesenberg F, Oeding P. Antibodies to staphylococcal peptidoglycan and its peptide epitopes, teichoic acid, and lipoteichoic acid in sera from blood donors and patients 
with staphylococcal infections. J Clin Microbiol. 1989;27(6):1286-91.

18. Mack D, Riedewald J, Rohde H, Magnus T, Feucht HH, Elsner HA et al. Essential functional role of the polysaccharide intercellular adhesin of Staphylococcus epidermidis in hemagglutination. Infect Immun. 1999;67(2):1004-8.

19. Bradford MM. A rapid and sensitive method for the quantitation of microgram quantities of protein utilizing the principle of protein-dye binding. Anal Biochem. 1976;72:248-54.

20. Dubois M, Gilles KA, Hamilton JK, Rebers P, Smith F. Colorimetric method for determination of sugars and related substances. Analytical chemistry. 1956;28(3):350-6.

21. Buslov DK, Nikonenko NA. A priori estimation of the parameters of the method of spectral curve deconvolution. Applied spectroscopy. 1998;52(4):613-20.

22. Haner RL, Keifer PA. Flow Probes for NMR Spectroscopy. eMagRes. 2007.

23. Al-Musawe. RNA. Exteraction and charactirazation of teichoic acid from staphylococcus aureus. Journal of Al-Nahrain University. 2008;11(2):119-22.
24. Spiliopoulou AI, Krevvata MI, Kolonitsiou F, Harris LG, Wilkinson TS, Davies AP et al. An extracellular Staphylococcus epidermidis polysaccharide: relation to Polysaccharide Intercellular Adhesin and its implication in phagocytosis. BMC Microbiol. 2012;12:76. doi:10.1186/1471-2180-12-76.

25. Kacurakova M, Mathlouthi M. FTIR and laser-Raman spectra of oligosaccharides in water: characterization of the glycosidic bond. Carbohydr Res. 1996;284(2):145-57.

26. Wicken AJ. The glycerol teichoic acid from the cell wall of Bacillus stearothermophilus B65. Biochem J. 1966;99(1):108-16.

27. Sadovskaya I, Vinogradov E, Li J, Jabbouri S. Structural elucidation of the extracellular and cell-wall teichoic acids of Staphylococcus epidermidis RP62A, a reference biofilm-positive strain. Carbohydr Res. 2004;339(8):1467-73. doi:10.1016/j.carres.2004.03.017. 